\title{
Relationship of socioeconomic status and oral-dental health in the Southeastern Anatolia
}

\author{
@Elif Pınar Bakır, @Özgün Kokoz Çitaker, @Şeyhmus Bakır \\ Dicle University, Faculty of Dentistry, Department of Restorative Dentistry, Diyarbakır, Turkey
}

Cite this article as: Bakır EP, Kokoz Çitaker Ö, Bakır Ş. Relationship of socioeconomic status and oral-dental health in the Southeastern Anatolia. J Health Sci Med 2021; 4(5): 622-629.

\begin{abstract}
Aim: Oral and dental health is affected by factors such as general health status, socioeconomic status. The aim of this study is to investigate the effects of socioeconomic status on DMFT and oral hygiene habits of patients.

Material and Method: 400 patients who applied to Dicle University Faculty of Dentistry Department of Restorative Dentistry for dental treatments were asked to fill in a questionnaire to reflect their oral hygiene habits along with their descriptive information and socioeconomic status. Clinical and radiological examinations of the patients were made, and the value of the DMFT index was determined for each patient. Statistical analysis was performed using Mann Whitney U and Chi-Square tests.

Results: According to our study, the education status, monthly income and frequency of tooth brushing affect the DMFT index value statistically significantly $(\mathrm{p}<0.05)$. Although $69.6 \%$ of those participating in the study are young people aged 35 and under, $46.3 \%$ do not work at any job; $84.2 \%$ of them can reach a monthly income of 4001 TL or less per month. In addition, $65.8 \%$ of the people participating in the survey think that their economic status affects oral and dental health. Those with the lowest monthly income have the highest DMFT confirms the opinion of the participants.

Conclusion: Based on the results of our study, in which we found that the disadvantaged socioeconomic situation had a negative impact on oral and dental health, we think that this situation can be improved with social state practices such as fluoride prophylaxis, distribution of oral hygiene equipment.
\end{abstract}

Keywords: Oral-dental health, socioeconomic status, DMFT

\section{INTRODUCTION}

Today, the different socioeconomic conditions of individuals have led to the idea that their access to health services and oral hygiene tools will not be equal.Living standards of different segments of society; changes according to criteria such as financial situation, place of residence, and this variability is also observed in the oral hygiene and treatment approaches of the patients. Neglected oral health can often cause tooth decay and gum disease, and if it continues, tooth loss. Dental caries causing conditions such as pain, aesthetics and loss of function, and the local effect, where the necessary treatments are not done on time, can turn into a systemic effect, which can deeply affect the general health, and this may rarely cause death (1-3). The prevalence of this situation has been found to be particularly high for socioeconomically disadvantaged groups (4).

Although oral-dental health is seen as a localized concept, many studies show that it is significantly associated with various systemic diseases $(5,6)$. Good oral hygiene; is one of the main factors of maintaining oral health as well as general health (7).

Individuals have been reported to be healthier as their socioeconomic status increases (8). Although it is more prominent in groups such as women, children and the elderly, the effects of differences in socioeconomic status on health; plays a significant role in the health of the whole society. The socioeconomic status affects the knowledge and attitudes of the parents on the subject, therefore it is a determining factor for the positive or negative effect of the parents on the child (9).

The DMFT (Carious, missing and filled teeth) index is one of the common methods used for nearly 80 years to assess the prevalence of dental caries and dental treatment needs among populations in oral epidemiology (10). The DMFT index is based on a field clinical examination of individuals using an end, mirror, and cotton rolls, and 
is simply detects the number of decayed, missing and restored teeth. Another version proposed in 1931 is the carious, incomplete and filled surface (DMFS) index by counting each affected surface, DMFT, the most widely used dental index by WHO, can be made using the least material, effort and time. It is an index that is simple, easy to apply clinically and can be supported with panoramic $\mathrm{x}$-rays, causing it to be used frequently.

The hypothesis of our study; Individuals with a high socioeconomic level will have better oral-dental health than those with low socioeconomic status; individuals with higher education level will have lower DMFT index values.

\section{MATERIAL AND METHOD}

Approval for the study was given by the Ethics Committee of Dicle University Faculty of Dentistry (Date: 27.01.2021, Decision No: 2021/07). All procedures were carried out in accordance with the ethical rules and the principles of the Declaration of Helsinki.

\section{Participants}

A questionnaire form was presented to a total of 400 patients who applied to Dicle University Faculty of Dentistry to evaluate the effect of their socioeconomic status on DMFT index values and oral hygiene habits with informed consent. Routine radiological and oral examinations of the patients were performed.

At the beginning of the form, there are questions describing the sociodemographic characteristics of the patients (age, gender, etc..). In the second part of the questionnaire, attitude and behavior evaluation questions such as oral hygiene habits of the patients and frequency of tooth brushing were asked. DMFT index values were also determined as a result of the clinical and radiological examinations of the patients; decayed teeth in the mouth, teeth restored with filling and lost teeth were calculated and included in the examination.

\section{Statistical Analysis}

After determining the socioeconomic status and oral hygiene habits, the relationship between the two parameters was evaluated statistically. Frequency distribution tables were created for general properties. Kolmogorov-Smirnov test was applied to determine the suitability of the DMFT index to normal distribution and p: 0.00 ; Since $p<0.05$, it was found that it did not show a normal distribution. In line with this result, the Mann Whithney $\mathrm{U}$ test was used to compare the DMFT index with the variables of 2 categories and the Kruskal-Wallis test for the comparison of the variables with more than 2 categories and the Chi square test for the comparison of the 2 categorical variables. The confidence interval is $95 \%$ and the significance value is $5 \%$.

\section{RESULTS}

According to results; $41.8 \%$ were in the $18-25$ age group, $27.8 \%$ in the $25-35$ age group, $19.3 \%$ in the $35-45$ age group, $7.8 \%$ in the $45-55$ age group, and A total of 400 patients participated, 3.5 of whom were 55 years of age or older. $57.8 \%$ of the participants are women and $42.3 \%$ are men. The general distribution is shown in Table 1 and Table 2.

\section{Table 1. Distribution of sociodemographic characteristics of} participants

\begin{tabular}{|c|c|c|}
\hline & $\mathbf{N}$ & $\%$ \\
\hline \multicolumn{3}{|l|}{ Age } \\
\hline $18-25$ & 167 & 41.8 \\
\hline $26-35$ & 111 & 27.8 \\
\hline $36-45$ & 77 & 19.3 \\
\hline $46-55$ & 31 & 7.8 \\
\hline 56 years and older & 14 & 3.5 \\
\hline \multicolumn{3}{|l|}{ Gender } \\
\hline Female & 231 & 57.8 \\
\hline Male & 169 & 42.3 \\
\hline \multicolumn{3}{|l|}{ Education } \\
\hline Literate/primary school & 76 & 19.0 \\
\hline Middle school & 65 & 16.3 \\
\hline High school & 133 & 33.3 \\
\hline University (undergraduate) & 118 & 29.5 \\
\hline Postgraduate/doctorate & 8 & 2.0 \\
\hline \multicolumn{3}{|l|}{ Profession } \\
\hline Artisan & 11 & 2.8 \\
\hline Officer & 51 & 12.8 \\
\hline Worker & 54 & 13.5 \\
\hline Unemployee & 185 & 46.3 \\
\hline Other & 99 & 24.8 \\
\hline \multicolumn{3}{|l|}{ Living Place } \\
\hline Village & 29 & 7.2 \\
\hline District & 68 & 17.0 \\
\hline Province & 303 & 75.8 \\
\hline \multicolumn{3}{|c|}{ Number of individuals in the family } \\
\hline $1-4$ & 130 & 32.5 \\
\hline $5-8$ & 212 & 53.0 \\
\hline Over 8 & 58 & 14.5 \\
\hline \multicolumn{3}{|l|}{ Health assurance } \\
\hline With & 312 & 78.0 \\
\hline With out & 88 & 22.0 \\
\hline \multicolumn{3}{|l|}{ Monthly income } \\
\hline 2000 TL and below & 203 & 50.7 \\
\hline $2001-4000 \mathrm{TL}$ & 134 & 33.5 \\
\hline $4001-6000 \mathrm{TL}$ & 39 & 9.8 \\
\hline $6001 \mathrm{TL}$ and above & 24 & 6.0 \\
\hline Total & 400 & 100 \\
\hline
\end{tabular}

The monthly income of $50.7 \%$ of the participants is 2000 $\mathrm{TL}$ and below, 33.5\% 2001-4000 TL, 9.8\% 4001-6000 TL and $6 \% 6001$ TLand above. While $11.5 \%$ of the participants never go to the dentist, $68.8 \%$, that is, the majority of them, when there is pain, $7 \%$ go every 6 months and $12.8 \%$ once a year. $80 \%$ of the individuals participating in the study think that oral and dental cleaning affects the general health. $56.3 \%$ of the participants use salty/ carbonated water prepared at home as a mouthwash, and $43.8 \%$ use ready-made solutions. 
Table 2. Findings on knowledge, attitudes and behaviors related to oral health and oral hygiene habits

\begin{tabular}{|c|c|c|c|}
\hline & & $\mathbf{N}$ & $\%$ \\
\hline \multirow{2}{*}{ Do you have any health problems? } & Yes & 44 & 11.0 \\
\hline & No & 356 & 89.0 \\
\hline \multirow{2}{*}{ Is there any medication you use regularly? } & Yes & 37 & 9.3 \\
\hline & No & 363 & 90.8 \\
\hline \multirow{4}{*}{ How often do you go to the dentist? } & No & 46 & 11.5 \\
\hline & When there is pain & 275 & 68.8 \\
\hline & Every 6 months & 28 & 7.0 \\
\hline & Once a year & 51 & 12.8 \\
\hline \multirow{2}{*}{ Do you think oral and dental hygiene affect general health? } & Yes & 320 & 80.0 \\
\hline & No & 78 & 19.5 \\
\hline \multirow{5}{*}{ How many times should teeth be brushed a day? } & 4 Times & 13 & 3.3 \\
\hline & 3 Times & 125 & 31.3 \\
\hline & 2 Times & 208 & 52.0 \\
\hline & 1 Time & 51 & 12.8 \\
\hline & Not brushed & 3 & 0.8 \\
\hline \multirow{4}{*}{ What is your brushing frequency? } & 2 times a day & 201 & 50.2 \\
\hline & Once a day & 134 & 33.5 \\
\hline & Rare & 59 & 14.8 \\
\hline & I never brush & 6 & 1.5 \\
\hline \multirow{5}{*}{ Which products do you use most for oral and dental cleaning? } & Toothbrush/toothpaste & 370 & 92.5 \\
\hline & Floss & 8 & 2.0 \\
\hline & Mouthwash & 6 & 1.5 \\
\hline & Toothpick & 15 & 3.8 \\
\hline & Miswak & 1 & 0.3 \\
\hline \multirow{2}{*}{ Do you think toothpaste brand affects oral hygiene? } & Yes & 300 & 75.0 \\
\hline & No & 100 & 25.0 \\
\hline \multirow{2}{*}{ Do you think toothpastes/toothbrushes are expensive? } & Yes & 260 & 65.0 \\
\hline & No & 140 & 35.0 \\
\hline \multirow{2}{*}{$\begin{array}{l}\text { Do you think dental cleaning products (dental floss, interface } \\
\text { brush, mouthwash, etc.) are expensive? }\end{array}$} & Yes & 271 & 67.8 \\
\hline & No & 129 & 32.3 \\
\hline \multirow{2}{*}{ Which one do you use as a mouthwash? } & Homemade salted/carbonated water & 225 & 56.3 \\
\hline & Ready-made mouthwash solutions & 175 & 43.8 \\
\hline \multirow{2}{*}{ Do you think dental treatments are expensive? } & Yes & 343 & 85.8 \\
\hline & No & 57 & 14.2 \\
\hline \multirow{4}{*}{ What is your smoking frequency? } & I don't use & 275 & 68.8 \\
\hline & Less than 1pack per day & 84 & 21.0 \\
\hline & 1 package per day & 34 & 8.5 \\
\hline & More than 1 packper day & 7 & 1.8 \\
\hline \multirow{2}{*}{$\begin{array}{l}\text { Do you think dental treatment costs (dental filling, tooth } \\
\text { extraction, prosthesis, implant, etc.) can be avoided by cleaning the } \\
\text { mouth? }\end{array}$} & Yes & 201 & 50.2 \\
\hline & No & 199 & 49.8 \\
\hline \multirow{2}{*}{$\begin{array}{l}\text { Do you think your economic situation affects your oral and dental } \\
\text { health? }\end{array}$} & Yes & 263 & 65.8 \\
\hline & No & 137 & 34.3 \\
\hline \multirow{2}{*}{$\begin{array}{l}\text { Have you received oral and dental health training from your } \\
\text { mother/father as a child? }\end{array}$} & Yes i got & 181 & 45.3 \\
\hline & No i didn't get & 219 & 54.8 \\
\hline \multirow{2}{*}{ Did your parents have a habit of brushing teeth? } & Yes & 226 & 56.5 \\
\hline & No & 174 & 43.5 \\
\hline Total & & 400 & 100 \\
\hline
\end{tabular}

$75 \%$ of the respondents think that the toothpaste brand affects oral hygiene and $65 \%$ think that toothpaste and brushes are expensive. $67.8 \%$ of the participants stated that dental cleaning products (dental floss, interface brush, mouthwash, etc.) are expensive. The majority of the participants $(85.8 \%)$ think that dental treatments are expensive. $50.2 \%$ think that dental treatment (dental filling, tooth extraction, prosthesis, implant, etc.) costs can be avoided by cleaning the mouth. $65.8 \%$ of the participants think that their economic conditions affect their oral and dental health.

There is a statistically significant difference between the educational status of the participants and their 


\begin{tabular}{|c|c|c|c|}
\hline & $\begin{array}{c}\text { Rank } \\
\text { averages }\end{array}$ & $\mathrm{X} 2 / \mathrm{z}$ & $\mathbf{P}$ \\
\hline Education & & 13.832 & 0.008 \\
\hline Literate/primary school & 232.12 & & \\
\hline Middle school & 208.82 & & \\
\hline High school & 205.14 & & \\
\hline University (undergraduate) & 172.50 & & \\
\hline Postgraduate/doctorate & 168.38 & & \\
\hline Monthly income & & 14.026 & 0.003 \\
\hline 2000 TL and below & 207.67 & & \\
\hline $2001-4000 \mathrm{TL}$ & 204.57 & & \\
\hline $4001-6000 \mathrm{TL}$ & 201.59 & & \\
\hline $6001 \mathrm{TL}$ and above & 115.35 & & \\
\hline Living place & & 0.025 & 0.988 \\
\hline Village & 197.98 & & \\
\hline District & 199.45 & & \\
\hline Province & 200.98 & & \\
\hline How often do you go to the dentist? & & 6.966 & 0.073 \\
\hline No & 178.41 & & \\
\hline When there is pain & 209.13 & & \\
\hline Every 6 months & 207.98 & & \\
\hline Once a year & 169.75 & & \\
\hline What is your brushing frequency? & & 8.187 & 0.042 \\
\hline 2 times a day & 194.59 & & \\
\hline Once a day & 191.30 & & \\
\hline Rare & 236.87 & & \\
\hline I never brush & 246.25 & & \\
\hline $\begin{array}{l}\text { Have you received oral and dental hea } \\
\text { from your mother/father as a child? }\end{array}$ & th training & 21.124 & 0.256 \\
\hline Yes, i got & 193.29 & & \\
\hline No,i didn't get & 206.46 & & \\
\hline
\end{tabular}

DMFT index $(\mathrm{p}<0.05)$. Participants whose educational background is literate/primary school have the highest DMFT index and the participants with graduate education have the lowest.

There is a statistically significant difference between the monthly income of the participants and their DMFT index $(\mathrm{p}<0.05)$. Participants with a monthly income of TL 2000 and below have the highest DMFT index values, whereas participants with a monthly income of $6001 \mathrm{TL}$ and above have the lowest values.

There is a statistically significant difference between the frequency of brushing of the participants and their DMFT index $(\mathrm{p}<0.05)$. Participants who never brush their teeth had the highest DMFT index values and those who brushed once a day had the lowest DMFT index values.

No significant relationship was found between the monthly income and the type of mouth/teeth cleaning products they use the most and also, between monthly income and the situation of thinking that dental treatments are expensive as a continuation of toothpaste and brushes, dental cleaning products $(p>0.05)$. There is a statistically significant difference between the opinions of the participants about the required frequency of brushing and their parents having a habit of brushing their teeth $(\mathrm{p}<0.05)$.

This situation is shown in Table 4 and Table 5.

\begin{tabular}{|c|c|c|c|c|c|c|c|}
\hline & & \multicolumn{4}{|c|}{ Monthly income } & \multirow[b]{2}{*}{$\mathrm{X} 2$} & \multirow[b]{2}{*}{$\mathbf{P}$} \\
\hline & & $\begin{array}{l}2000 \mathrm{TL} \text { and } \\
\text { below }\end{array}$ & $\begin{array}{l}2001-4000 \\
\text { TL }\end{array}$ & $\begin{array}{l}4001-6000 \\
\text { TL }\end{array}$ & $\begin{array}{c}6001 \mathrm{TL} \text { and } \\
\text { above }\end{array}$ & & \\
\hline \multirow{5}{*}{$\begin{array}{l}\text { Which products do you use most for } \\
\text { oral and dental cleaning? }\end{array}$} & Toothbrush/toothpaste & $186(91.6 \%)$ & $123(91.8 \%)$ & $37(94.9)$ & $24(100 \%)$ & \multirow{5}{*}{6.925} & \multirow{5}{*}{0.863} \\
\hline & Floss & $4(2 \%)$ & $3(2.2 \%)$ & $1(2.6 \%)$ & 0 & & \\
\hline & Mouthwash & $4(2 \%)$ & $2(1.5 \%)$ & 0 & 0 & & \\
\hline & Toothpick & $8(3.9 \%)$ & $6(4.5 \%)$ & $1(2.6 \%)$ & 0 & & \\
\hline & Miswak & $1(0.5 \%)$ & 0 & 0 & 0 & & \\
\hline \multirow{2}{*}{$\begin{array}{l}\text { Do you think toothpastes/toothbrushes } \\
\text { are expensive? }\end{array}$} & Yes & $12762.6 \%)$ & $87(64.9 \%)$ & $30(76.9 \%)$ & $16(66.7 \%)$ & \multirow{2}{*}{2.997} & \multirow{2}{*}{0.392} \\
\hline & No & $76(37.4 \%)$ & $47(35.1 \%)$ & $9(23.1 \%)$ & $8(33.3 \%)$ & & \\
\hline \multirow{2}{*}{$\begin{array}{l}\text { Do you think dental cleaning } \\
\text { products (dental floss, interface brush, } \\
\text { mouthwash, etc.) are expensive? }\end{array}$} & Yes & $133(65.5 \%)$ & $91(67.9 \%)$ & $30(76.9 \%)$ & $17(70.8 \%)$ & \multirow{2}{*}{2.071} & \multirow{2}{*}{0.558} \\
\hline & No & $70(34.5 \%)$ & $43(32.1 \%)$ & $9(23.1 \%)$ & $7(29.2 \%)$ & & \\
\hline \multirow{2}{*}{$\begin{array}{l}\text { Do you think dental treatments are } \\
\text { expensive? }\end{array}$} & Yes & $176(86.7 \%)$ & $114(85.1 \%)$ & $34(87.2 \%)$ & $19(79.2 \%)$ & \multirow{2}{*}{1.116} & \multirow{2}{*}{0.773} \\
\hline & No & 27 (13.3\%) & $20(14.9 \%)$ & $5(12.8 \%)$ & $5(20.8 \%)$ & & \\
\hline \multirow{2}{*}{$\begin{array}{l}\text { Do you think your economic situation } \\
\text { affects your oral and dental health? }\end{array}$} & Yes & $131(64.5 \%)$ & $89(66.4 \%)$ & $28(71.8 \%)$ & $15(62.5 \%)$ & \multirow{2}{*}{0.906} & \multirow{2}{*}{0.824} \\
\hline & No & $72(35.5 \%)$ & $45(33.6 \%)$ & $11(28.2 \%)$ & $9(37.5 \%)$ & & \\
\hline
\end{tabular}

Table 5. The relationship between toothbrushing knowledge level and parental behavior

\begin{tabular}{|c|c|c|c|c|c|c|c|c|}
\hline & & \multicolumn{5}{|c|}{ How many times should teeth be brushed a day? } & \multirow{2}{*}{$\mathrm{X} 2$} & \multirow{2}{*}{$\mathbf{p}$} \\
\hline & & 4 times & 3 times & 2 times & 1 time & Not brushed & & \\
\hline \multirow{2}{*}{$\begin{array}{l}\text { Have you received oral and dental } \\
\text { health training from your mother/ } \\
\text { father as a child? }\end{array}$} & Yes, i got & $4(2.2 \%)$ & $65(35.9 \%)$ & $92(50.8 \%)$ & $20(11 \%)$ & 0 & \multirow{2}{*}{6.715} & \multirow{2}{*}{0.152} \\
\hline & No, i didn't get & $9(4.1 \%)$ & $60(27.4 \%)$ & $116(53 \%)$ & $31(14.2 \%)$ & $3(1.4 \%)$ & & \\
\hline \multirow{2}{*}{$\begin{array}{l}\text { Did your parents have a habit of } \\
\text { brushing teeth? }\end{array}$} & Yes & $6(2.7 \%)$ & $80(35.4 \%)$ & $117(51.8 \%)$ & $23(10.2 \%)$ & 0 & \multirow{2}{*}{10.027} & \multirow{2}{*}{0.040} \\
\hline & No & $7(4 \%)$ & $45(25.9 \%)$ & $91(52.3 \%)$ & $28(16.1 \%)$ & $3(0.8 \%)$ & & \\
\hline
\end{tabular}




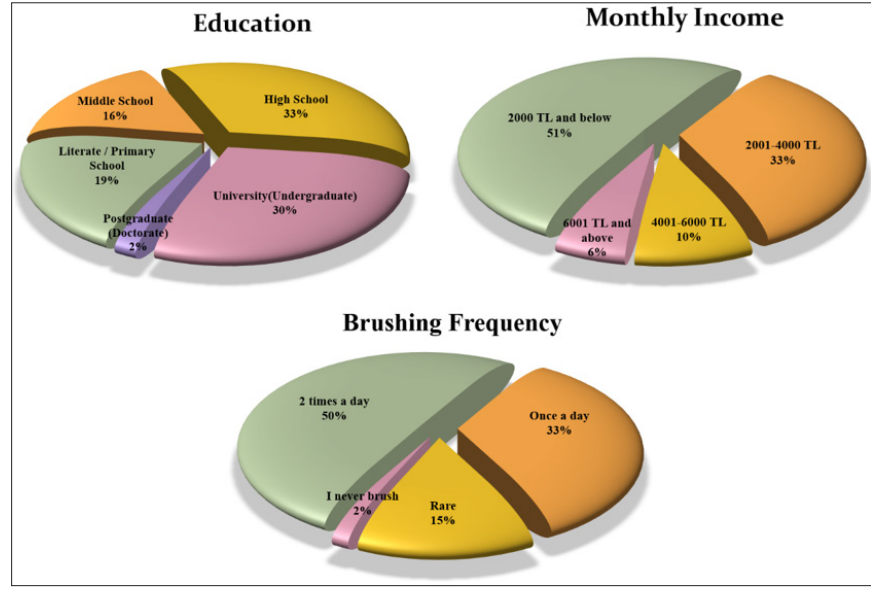

Figure.

\section{DISCUSSION}

Socioeconomic conditions of societies also change with the change of living conditions. Socioeconomic status, which is a multi-factor concept; It is effective in all areas of life, factors such as monthly income and education level of individuals affect their access to health equipment and services, and the quality of the health service they receive.

In this study, by determining the socioeconomic conditions and oral health conditions of the patients who applied to Dicle University Faculty of Dentistry; Oral and dental health habits, access to oral hygiene tools and attitudes, behaviors and thoughts on the subject were evaluated.

Although the effects of social inequalities on oral health are observed in studies on human societies, it is difficult to evaluate the impact of socioeconomic differences in all aspects $(11,12)$. Therefore, much more and detailed examination is required in order to have an idea about the impact of socioeconomic variables.

In the health model they developed Whitehead and Dahlgren (13) define healthy lifestyle behaviors as a result of the socioeconomic environment beyond being an individual preference. In our study, the majority of the participants think that their economic conditions affect their oral and dental health, and their oral health status also affects their general health.

Rupasree et al. (14) concluded that there is a strong correlation between lifestyle, education level and socioeconomic status and periodontal diseases. Among the participants in our study, those who were literate/ primary school staining compared to the other groups with the highest level of DMFT index knowledge. However, the low DMFT index value suggests that graduate students have an effect on teeth.

Astrom et al. (15) stated in their study that individuals belonging to higher income groups had lower rates of reporting toothache and were more likely to be satisfied with their oral and dental health status than those in the lower socioeconomic group. In addition to the positive correlation between monthly income and DMFT, we think that education level, which is one of the factors that can provide higher socioeconomic opportunities, may also be effective in this issue.

Wennstrom et al. (16) conducted a study on trends in tooth loss in Swedish women and observed that women in lower socioeconomic groups tend to have fewer teeth, regardless of their age. This study shows that monthly income is an important factor on the DMFT value, as in our study, and our study supports the literature in this respect.

Tooth brushing is the main mechanical method of plaque elimination and therefore has been shown to reduce the risk of developing dental diseases. It should be kept in mind that dental caries and periodontal diseases, which are diseases that can be prevented by regular tooth brushing, may cause tooth loss, and this will increase the rate of missing teeth scored in the DMFT index (17).

Yadav conducted a study on his brushing habit and stated that his elders had never used toothbrushes until that day and instead used Neem and Babool branches. In our study, $92.5 \%$ of the participants stated that they mostly used toothbrush/toothpaste for cleaning their mouth and teeth, while the rate of those who stated that they used the natural tree branch, miswak, remained at $0.3 \%$. This situation may suggest that the region and cultural factors are also effective on oral and dental health.

Again, Yadav's next focus (18) was the price of toothbrushes purchased by consumers, the economic situation; assessed the effect of individuals on access to oral and dental health supplies. Most of the consumers stated that they prefer to buy toothbrushes in promotional packages such as "buy two instead of one" in order to get extra profit, and that economic factors are effective in their choice of brushes. The findings support our findings in that individuals find oral dental health products expensive and monthly income affects their brushing habits.

Agata et al. (19) suggesting that individuals who have visited a dentist in the last 3 months and brushed their teeth 3 times a day have less chronic kidney disease, hypertension or diabetes, most of the hemodialized patients had an appointment with a dentist at the earliest one year before filling out the questionnaire, or what was the last They stated that they did not remember that they had time appointments. This result may show the effect of general health on oral and dental health. The vast majority of the individuals in our study also think that oral and dental hygiene affects their general health.

Gaurav et al. (20) reported that the use of even tongue cleaner was significantly higher in the upper middle 
socioeconomic class patients, whereas the majority $(81.3 \%)$ of the individuals in the lower socioeconomic class did not go to a dentist at all. The result of this study, which states that monthly income and economic level affect oral hygiene habits and accessibility, is also in line with our findings.

Singh et al. (21) in a study conducted among adults, showed that individuals in lower socioeconomic positions tend to cluster to a higher degree of multiple risk factors for worse oral and dental hygiene than those in higher socioeconomic positions. Here, it can be shown that individuals with a high economic level can purchase oral hygiene products and the frequency of going to the dentist for controls creates less economic problems.

Hooleyetal.(22) suggests that peoplefrom socioeconomic classes considered higher develop tooth decay at a slower rate than people with low socioeconomic status, due to a more tooth-friendly diet and increased access to fluoride. In our study, the rate of those who can reach fluoride-containing mouthwash cannot even reach half of the participants. We think that this situation is related not only to financial situation but also to the level of oral hygiene awareness.

Elger et al. (23) in their study concluded that oral dental health was affected by socioeconomic status. It has been suggested that diets that cause obesity are seen more in those with a high socioeconomic level and this may cause a high DMFT level. Environmental factors such as the place of residence, economic factors such as monthly income, or personal factors such as obesity are also determinants. However, it is stated that regular tooth brushing is the primary factor in the prevention of caries.

Rani et al. (24) found that children who don't use toothbrushes have a higher rate of tooth decay, they reported that the children of families with good socioeconomic status were more likely to brush their teeth.

Salamaa et al. (25) argued that socioeconomic status has an effect on the knowledge, attitudes and practices of parents and may affect their children's health status in general and oral health in particular, depending on the level of parental care. However, regarding the oral hygiene status of the children (the number of filled and decayed teeth), it showed that there was a statistically significant difference between the number of filled and decayed teeth, which was related to the mothers' level of knowledge. In our study, almost half of the participants answered positively to the question of "Did you receive oral dental health education from your parents as a child", but in paired comparisons, this situation did not have a significant effect on their opinions about the number of daily brushing teeth required.
Tooth decay, as a multifactorial disease, follows a chronic process that is also affected by environmental factors and cultural factors. It is a generally accepted inference that mothers' knowledge of oral hygiene, attitudes and behaviors supportive of oral hygiene also affect the dental health of children. However, in our study, no statistically significant difference was found between the oral and dental health education/DMFT value received from the mother/father. Bali et al. showed that children in the higher socioeconomic group were at a lower risk of caries. However, it has been reported that children from families with lower socioeconomic status are at greater risk for the development of dental caries, in line with the literature $(26,27)$. In our study, the DMFT indexes of participants with a monthly income of $2000 \mathrm{TL}$ or less were found to be the highest, however. The DMFT index of the participants with a monthly income of $6001 \mathrm{TL}$ and above was found to be the lowest and it was thought that the economic situation could be more effective on oral health than thought.

Marchesan et al. In their study conducted in 2020, they evaluated the relationship between dental floss use and oral diseases among the elderly, and as a result of a 5 -year observation and follow-up, they found that people using dental floss had less periodontitis, caries and tooth loss. In our study, $60 \%$ to $70 \%$ of participants in all income groups reported that they found oral hygiene tools, including dental floss, expensive. It is ignored that a small amount of floss can clean the whole mouth, and a box of floss can be used for a long time. Majority of the participants defined the hygiene tool they use the most as a toothbrush/paste, and a very small portion stated that they used dental floss more. We think that this is a result of the perception of the cost of flossing as well as the idea of applying flossing to all interdental areas one by one, causing laziness (28).

On the other hand, Neamatollahi and Ebrahimi (29) reported that doctoral and graduate students tend to use dental floss more frequently than undergraduate students. The study conducted supports the significant relationship we found between education and DMFT.

Oral and dental health problems are seen as a common public health problem, and socioeconomic factors are also effective according to research findings. The $\mathrm{HO}$ hypothesis is that socio-economic status has no effect on community oral and dental health. And The $\mathrm{H} 0$ hypothesis was rejected according to the results of our study, in which we found that the disadvantaged socioeconomic situation had a negative effect on oral and dental health. We are of the opinion that the problem can be solved by addressing all its dimensions through improvements in health insurance and social state policies. 


\section{CONCLUSION}

In the light of the data obtained in our study, it can be mentioned that there is a positive correlation between the educational status and monthly income of the individuals and their brushing habits. Patients who think that the price of toothpaste/toothbrush, which is the basic oral hygiene tool, is expensive, also think that dental treatments are expensive and their socioeconomic status affects their oral and dental health. Since this point of view is expensive, it can lead to avoidance of toothbrush/paste use, decrease in dentist visits and eventually deterioration of oral health.

With the improvements to be made regarding the social situation, economic conditions, the quality and content of education, the oral and dental health of individuals can be protected and access to health services and tools, one of the basic human rights, can be provided.

\section{ETHICAL DECLARATIONS}

Ethics Committee Approval: Approval for the study was given by the Ethics Committee of Dicle University Faculty of Dentistry (Date: 27.01.2021, Decision No: 2021/07).

Informed Consent: All patients signed the free and informed consent form.

Referee Evaluation Process: Externally peer-reviewed. Conflict of Interest Statement: The authors have no conflicts of interest to declare.

Financial Disclosure: The authors declared that this study has received no financial support.

Author Contributions: All of the authors declare that they have all participated in the design, execution, and analysis of the paper, and that they have approved the final version.

Acknowledgements: We would like to thank all healthcare professionals that agreed to share their perspectives.

\section{REFERENCES}

1. Broadbent ve diğerleri, 2008] (Broadbent JM, Thomson WM, Poulton R: Trajectory patterns of dental caries experience in the permanent dentition to the fourth decade of life. J Dent Res 2008; 87: 69-72

2. Glockmann E, Panzner K, Huhn P, Sigusch B, Glockmann K Ursachen des Zahnverlustes in Deutschland-Dokumentation einer bundesweiten Erhebung (2007) [Reasons for tooth loss in Germany-documentation of a nationwide survey (2007)]. Köln (Germany): IDZ-Information, Institute of German Dentists (IDZ) 2011

3. WHO. Non-Communicable Diseases and Their Risk Factors, 2018. Available at: https: //www.who.int/news-room/fact-sheets/ detail/oral-healt. [accessed September 24, 2018].

4. Antunes J, Frazão P, Narvai P, Bispo C, Pegoretti T. Geographic Information Systems (GIS) in assessing dental health. Int Environ Res Public Health 2010; 7: 2423-36.
5. Jin LJ, Lamster IB, Greenspan JS, Pitts NB, Scully C, Warnakulasuriya S. Global burden of oral diseases: Emerging concepts, management and interplay with systemic health. Oral Dis 2016; 22: 609-19.

6. Linden GJ, Lyons A, Scannapieco FA. Periodontal systemic associations: Review of the evidence. J Clin Periodontol 2013; 40: 8-19.

7. Park J.B, Han K, Park YG, Ko Y. Association between socioeconomic status and oral health behaviors: The 2008-2010 Korea national health and nutrition examination survey. Exp Ther Med 2016; 12: 2657-64.

8. Matthews KA, Gallo LC. Psychological perspectives on pathways linking socioeconomic status and physical health. Annu Rev Psychol 2011; 62: 501-30.

9. Kumar N, Gupta N, Kishore J. Kuppuswamy's socioeconomic scale: Updating income ranges for the year 2012. Indian J Public Health 2012; 56: 103-4.

10. Broadbent JM, Thomson WM. For debate: problems with the DMF index pertinent to dental caries data analysis. Community Dent Oral Epidemiol 2005; 33: 400-9.

11. Steele J, Shen J, Tsakos G, et al. The Interplay between Socioeconomic Inequalities and Clinical Oral Health. J Dent Res 2015; 94: 19-26.

12. Thomson WM: Social inequality in oral health. Community Dent Oral Epidemiol 2012; 40: S28-S32.

13. Ireland Capital \& Health Survey. (2000). A Report on the allIreland capital \& health survey: Inequalities in perceived health. Erişim: 28.01.2006. http: //www.publichealth.ie

14. Rupasree Gundala, Vijay K. Chava. Effect of lifestyle, education and socioeconomic status on periodontal health: Contemp Clin Dent 2010; 1: 23-6.

15. Astrom AN, Haugejorden O, Skaret E, Trovik TA, Klock KS. Oral Impacts on daily performance in norwegian adults: The influence of age, number of missing teeth, and socio-demographic factors. Eur J Oral Sci 2006; 114: 115-21.

16. Wennstrom A, Ahlqwist M, Stenman U, Bjorkelund C, Hakeberg $\mathrm{M}$. Trends in tooth loss in relation to socio-economic status among Swedish women, aged 38 and 50 years: Repeated crosssectional surveys 1968-2004. BMC Oral Health 2013; 13: 632013.

17.Daly, GC. Prescribing good oral hygiene for adults. Aust Prescr, 2009 Jun; 32: 72-5. Available from: http: //www. australianprescriber.com/magazine/32/3/72/5/

18. Komal Yadav K. Consumer behaviour in relation to toothbrush marketing: a study on Jaipur District 2015 AIJRA Vol.II Issue III. ISSN 2455-5967.

19. Trzcionka A, Twardawa H, Mocny-Pachońska K, Tanasiewicz M. Oral cavity status of long-term hemodialized patients vs. their socio-economic status. Med Pr 2020; 71: 279-88.

20. Sharma G, Oberoi SS, Oberoi A. A cross-sectional survey to assess the effect of socioeconomic status on the oral hygiene habits J Indian Soc Periodontal 2016; 20: 531-42.

21.Singh A, Rouxel P, Watt R.G and Tsakos G: Social inequalities in clustering of oral health related behaviors in a national sample of British adults. Prev Med 2013; 57: 102-6.

22.Hooley M, Skouteris H, Boganin C, Satur J, Kilpatrick N. Body mass index and dental caries in children and adolescents: a systematic review of literature published 2004 to 2011. Syst Rev 2012; 1: e1520.

23. Elger W, Kiess W, Körner A, Schrock A, Vogel M, Hirsch C. Influence of overweight/obesity, socioeconomic status, and oral hygiene on caries in primary dentition. J Investig Clin Dent 2019; 10: e12394.

24. Rani S, Singh A, Virdi MS, Mehta LK. Impact of socioeconomic status on oral health and oral health practices among preschool children. J Adv Med Dent Sci Res 2017; 5. 
25. Salama Aml A, Konsowa Eslam M, Alkalash Safa H. Mothers' knowledge, attitude, and practice regarding their primary school children's oral hygiene. Menoufia Med J 2020; 33: 11-7.

26. Bali RK, Mathur VB, Talwar PP, Chanana HB. National Oral Health Survey and Fluoride Mapping 2002-2003 India. 1st ed. New Delhi: Dental Council of India and Ministry of Health and Family Welfare, Government of India; 2004.

27. Touger-Decker R, Mobley C. Academy of Nutrition and Dietetics. Position of the Academy of Nutrition and Dietetics: Oral health and nutrition. J Acad Nutr Diet 2013; 113: 693-701.

28. Marchesan JT, Byrd KM, Moss K, et al. Flossing is associated with improved oral health in older adults. J Dent Res 2020; 99: 1047-53.

29. Neamatollahi H, Ebrahimi M. Oral health behavior and its determinants in a group of Iranian students. Indian J Dent Res 2010; 21: 84-8. 